\title{
Tribological Behavior of Tool Steel Substrate and Solid Films against 304 BA Austenitic Stainless Steel under Dry Sliding
}

\author{
Natchanun Angsuseranee (D), 1,2 Bhadpiroon Watcharasresomroeng, \\ Pracha Bunyawanichkul, ${ }^{1}$ and Siradej Chartniyom ${ }^{3}$ \\ ${ }^{1}$ Department of Mechanical Engineering, Srinakharinwirot University, Nakhonnayok 26120, Thailand \\ ${ }^{2}$ Tool and Die Technology Center (TDTC), Rajamangala University of Technology Suvarnabhumi, Nonthaburi, 11000, Thailand \\ ${ }^{3}$ Department of Industrial Engineering, Srinakharinwirot University, Nakhonnayok 26120, Thailand
}

Correspondence should be addressed to Natchanun Angsuseranee; natchanun.a@rmutsb.ac.th

Received 7 June 2020; Revised 27 July 2020; Accepted 31 July 2020; Published 4 September 2020

Academic Editor: João P. Davim

Copyright (C) 2020 Natchanun Angsuseranee et al. This is an open access article distributed under the Creative Commons Attribution License, which permits unrestricted use, distribution, and reproduction in any medium, provided the original work is properly cited.

\begin{abstract}
The objective of this work is to study the tribological behavior of the contacting surfaces of SKD11 grade hardened cold work tool steel against grade SUS304BA austenitic stainless steel. DLC, CrN, TiN, and TiCN films were coated on the surface of the tool material to test the tribological performance. Simulation testing with a pin-on-disk was used in this study. The study was done under dry conditions with sliding velocities at 50,100 , and $150 \mathrm{~mm} / \mathrm{s}$ and contact pressures of 807,1095 , and $1280 \mathrm{MPa}$. The results show that the main problem is the adhesion of the workpiece material on the tool surface. The severity of the adhesion from the workpiece material is proportional to the sliding velocity and the contact pressure between the contacting surfaces. The coefficient of friction between the contacting surfaces has a positive relationship with the adhesion occurring on the tool surface. The hardness of the film coating is useful for preventing wear of the tool material, especially under high pressure between the contacting surfaces. However, it does not prevent the adhesion of workpiece material of low sliding velocity and low contact pressure conditions. Noncoated SKD11 tool steel has better effectiveness of adhesion performance than CrN, TiN, and TiCN film coatings.
\end{abstract}

\section{Introduction}

Tribological behavior between the contacting surfaces of tool and workpiece materials is the key for success in the metal forming process and even getting the shape as needed; however, that might not be enough because of the die existence and the surface quality of the workpiece after forming must also have been considered. Therefore, in the metal forming process, lubricants are typically used to improve the tribological properties between the contacting surfaces of the workpiece and the forming tools to reduce friction, wear, and forming forces [1]. However, lubricants are detrimental to the environment $[2,3]$, so there are efforts to avoid using or reducing lubricant amounts in metal forming processes.

Metal forming without lubricants shows that the workpiece material tends to transfer and adhere to the forming tools, especially when forming materials such as aluminum, stainless steel, and high strength steel (HSS), which leads to the poor surface quality of the formed workpiece after forming and extensive tool wear. Therefore, many investigations are interested in using surface engineering techniques to solve such problems.

Murakawa et al. [3] applied a diamond-like carbon (DLC) film on a deep drawing die surface to form 5000 series aluminum alloy sheets without using lubricants. It could perform more than 5,000 cups since the die surface did not remain adhered to the workpiece material, whereas adhesion had occurred on the surface of SKD11 noncoated die by the first forming. These results are consistent with the research of Horiuchi et al. [4]. Sato \& Besshi [5] reported that using a die made from cemented carbide is effective in preventing workpiece material adhesion in U-bending grade 1050 and 
5052 aluminum alloy better than a die that is made from grade SKD11 cold work tool steel, hardened and coated with TiC, TiN, and $\mathrm{CrN}$ films or a die made from SKH51 hardened high-speed steel and then coated with DLC film [6].

Kataoka et al. [7] chose ceramic tools for deep drawing aluminum and stainless-steel sheets due to its effectiveness in preventing workpiece material adhesion on the die surface in dry forming. Podgornik et al. $[8,9]$ used a load-scanning test to study the tribological behavior between the contacting surfaces of VANADIS 4 tool steel materials coated with various types of film coatings with aluminum and stainless steel. They found that the tool steel coated with $\mathrm{TiN}, \mathrm{TiB}_{2}$, $\mathrm{VN}, \mathrm{TaC}$, and DLC films have properties to prevent aluminum adhesion on the surface of the tool material, and DLC film provided the best result in preventing stainless steel from adhering on the surface of tool steel, even in testing conditions that do not use lubricants. In addition, the efficiency of the film coatings to prevent adhesion can be increased by substrate preparation to smooth the surface before coating with a film. Abe et al. [10] improved the surface properties of the die for ironing aluminum and stainless-steel sheet materials by creating fine lubricant pockets on the die land surface. The operation can be performed to increase the efficiency of preventing the adhesion of workpiece material on the die surface, especially the combination of the technique with TiCN-cermet die and mineral oil usage. Gåård et al. and Karlsson et al. [11, 12] concluded that the microstructure and hardness of tool steel material influenced the antiadhesion performance of stainless steel and HSS workpiece materials using tribological tests with a slider-on-flat surface tribometer.

Kim et al. [13] used strip drawing testing to examine the efficiency of film coatings to prevent workpiece material adhesion on the tool steel surface. A TiCN film-coated tool is the most effective for preventing grade 980 advanced high strength steel (AHSS) from adhering to the die surface when compared to uncoated dies and other types of film coatings. Sresomroeng et al. [14-16] used several film coatings deposited on the die surface for U-bending HSS and AHSS workpiece materials. The results show that $\mathrm{CrN}$ film is effective in preventing the adhesion of those material types to the die surface. To increase the bonding strength of the film coating to the tool steel substrate, it is necessary to prolong the film usage when it is required to form a workpiece material that produces high contact pressure during forming. Choi et al. [17] improved the performance of the grade AISI D2 tool steel material in preventing the adhesion of grade DP980 AHSS by using TiAlCrN hard film coatings. Abe et al. [18] reported that using a die made from SKD 11 cold work tool steel and coated with VC by thermal diffusion (TD) has proven effective in preventing adhesion on the die surfaces for the ironing process of $1180 \mathrm{MPa}$ steel. This is consistent with the results of Wang et al. [19], who used VC coatings with DC53 tool steel to prevent the adhesion of DP600 materials in a custom-designed sheet strip tribolotester.

The previous works demonstrate that different tribological conditions between the workpiece with relative movement on the tool surface during forming affected the quality of the contacting material surface due to adhesion problems, especially in nonlubricated conditions. In addition to the type of material, the surface roughness of the contacting surface, the forming velocity, and the contact pressure between the die and workpiece material are important parameters for the efficiency of the metal forming process. Therefore, it is important to understand the tribological behavior between the contacting surfaces of the die and the workpiece material by several of the forming process parameters, to support decision making in designing tools and determining the variables of the forming process appropriately.

Although cold forming stainless-steel tends to have severe problems with adhesion on cold work tool steel surfaces, using a solid film applied on the surface of the forming tool tends to solve the problem. However, the previous investigations still lack insight into the wear mechanism of cold work tool steel relative to the sliding movement of the workpiece materials in cold forming operations [20]; therefore, this work is interested in this issue as well, especially using PVD-deposited films to increase the tribological efficiency of the metal forming tool surface, which is one of the production costs. Presently, there are many types of films to choose from, each of which can work well with the different types of tool materials [16]. This study uses simulation testing for tribology, which is an economic method, as a means to study the influence of process parameters on sheet metal forming in dry conditions using wear testing, per ASTM G99-95a standard, between the contacting surfaces of tool materials with and without a solid film coating on the stainless steel sheet. The tribological behavior between the contacting surfaces of mating materials is reported and discussed in this research.

\section{Materials and Methods}

2.1. Materials. The contacting material that was studied is grade JIS-SKD11 cold work tool steel or equivalent AISI D2, which is commonly used in the tool and die industry. It was hardened and coated with various types of commercial solid films. Workpiece materials that have good anticorrosion properties, such as 304 BA (Bright-Annealed: highly reflective finish produced by cold rolling, bright annealing, and temper rolling) austenitic stainless steel, are widely used in many industries. The chemical composition of both materials was investigated by optical emission spectroscopy (OES). The mechanical properties of SUS304 BA stainless steel were obtained by tensile tests following ASTM E8 [21]. The results of the mechanical properties and chemical compositions of the studied materials are shown in Table 1.

2.2. Tribological Test. Anton Paar Pin-on-Disk Tribometer, rotating movement type, was used for studying the tribological behavior between contacting surfaces by pin-on-disk testing following ASTM G 99-95a [22] under dry conditions. Sliding velocity was studied at 3 levels, 50, 100 and $150 \mathrm{~mm} /$ $\mathrm{s}$, which corresponds to the velocity range in conventional 
TABLE 1: Mechanical properties and chemical compositions of the studied materials.

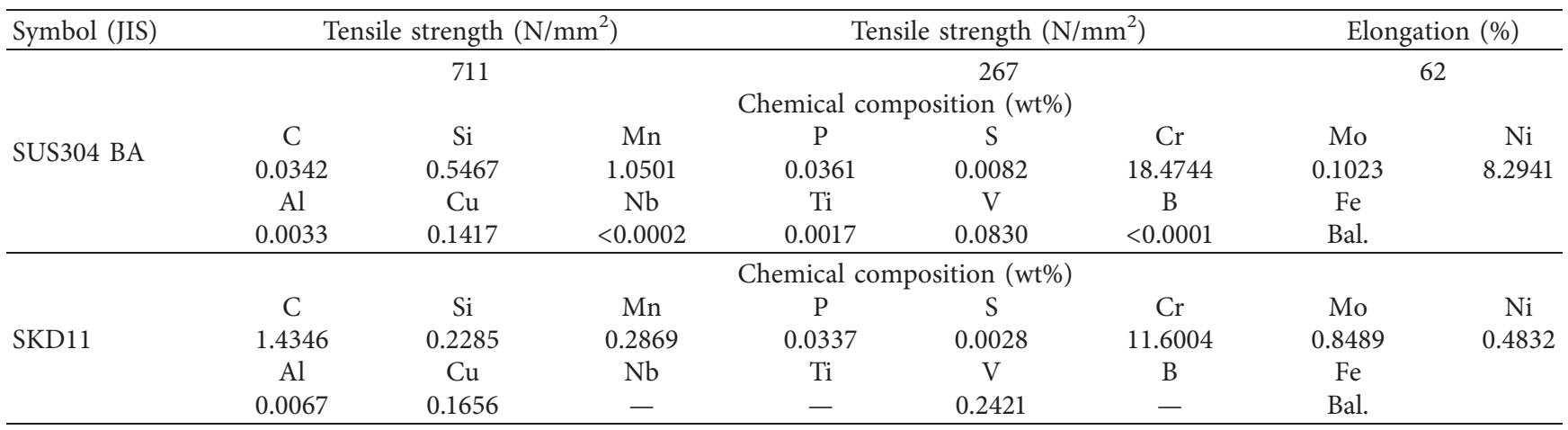

sheet metal forming processes [10, 11, 23] (i.e., bending, deep drawing, and blanking operation) and the pressure generated between the contacting surfaces of the tool material and sheet metal, which may be high at $1247 \mathrm{MPa}$ [24], especially with high strength materials. Therefore, the tests used normal loads at 2,5 , and $8 \mathrm{~N}$, which are equivalent to contact pressures of 807,1095 , and $1280 \mathrm{MPa}$, according to the Hertzian contact equation [25].

The $6 \mathrm{~mm}$ SKD11 ball was held by the ball holder instead of a pin for pin-on-disk testing. The ball was hardened to achieve $60 \pm 2$ HRC hardness values with surface finishing to get an arithmetic average roughness $\mathrm{Ra}$ of $0.1 \pm 0.05 \mu \mathrm{m}$. These hardness and surface roughness values are typically used with metal forming dies [3, 26-29]. An $\mathrm{Ra}$ of $0.1 \mu \mathrm{m}$ has been reported to increase the tool life of SKD 11 tool steel from adhesion when compared to a smoother polished surface [30]. The disks were prepared to be $30 \mathrm{~mm}$ in diameter from a $2 \mathrm{~mm}$ thick sheet of grade SUS304 BA stainless steel with electrodischarge machining (EDM) to prevent deformation. The tests were conducted in a control room at a temperature and relative humidity of $23 \pm 2^{\circ} \mathrm{C}$ and $50 \pm 3 \%$, respectively. The balls and disks were ultrasonically cleaned with acetone for 2 minutes before testing to ensure dry sliding contact.

The coefficient of friction between the contacting surfaces was determined using InstrumX software version 7.0.10, which was attached to the Tribometer test kit. The reported values are the mean value of the coefficient of friction for a $100 \mathrm{~m}$ sliding distance. Every $100 \mathrm{~m}$ of sliding distance up to $1200 \mathrm{~m}$, the ball was removed to investigate the damaged surface characteristics using a Mitutoyo Vision Unit microscope to snap a wear scar picture and measure wear scar area, as shown in Figure 1. Wear volume was calculated geometrically, as expressed by equation (1). The specific wear rate was calculated according to the Archard equation:

$$
\begin{aligned}
& V=\pi h^{2}\left(r-\frac{h}{3}\right), \\
& k=\frac{V}{F_{N} S},
\end{aligned}
$$

$V=$ wear volume $\left(\mathrm{mm}^{3}\right) \cdot h=$ distance from the arc of the ball to the wear scar $(\mathrm{mm}) . r=$ ball radius $(\mathrm{mm}) . k=$ specific wear rate $\left(\mathrm{mm}^{3} / \mathrm{Nm}\right) . F_{N}=$ normal load $(\mathrm{N}) . S=$ sliding distance $(\mathrm{m})$.
The quantitative analysis of the workpiece material adhesion on the ball surface was accessed by the percentage of adhesion area, which can be obtained from the ratio of the adhesion area to the total wear scar area on the contact surface of the ball multiplied by one hundred. The total wear scar area was measured from the image obtained using the Mitutoyo Vision Unit and using image processing techniques to assess the area of adhesion with the threshold operation. This technique was used to evaluate adherence material on mating surfaces in previous works $[5,6,31]$.

2.3. Film Coatings. To provide information to the industrial sector, a commercial film was chosen by considering the types of solid films used for this test in previous research data. All solid films were applied using a physical vapor deposition (PVD) coating process, which provides a smooth a thin layer of film [32] that is suitable for coating tool surfaces that require dimensional tolerance after coating. The thickness of the film layer on the surface of the die material was observed from the ball cross section using a HITASHI TM-1000 scanning electron microscope (SEM). The hardness of film coatings was measured using a HYSITRON Ti-Premier nanoindenter with a linearly increasing $0-1000 \mu \mathrm{N}$ normal load and $50 \mathrm{~nm}$ normal displacement. For each specimen, indentations on the coating were made at 5 different locations. The surface roughness of the solid film was examined using a stylus roughness tester with an $8.6 \mathrm{~mm}$ test distance and a $0.8 \mathrm{~mm}$ cut-off length. The physical and mechanical properties of the studied solid films are shown in Table 2.

\section{Results and Discussion}

3.1. Surface Characteristics of Hardened SKD11 Balls. Figure 2 shows the surface characteristics of the ball tested under various conditions after $1200 \mathrm{~m}$ test distance. The figure shows that the damage to the hardened SKD11 balls has 3 forms, abrasive wear, adhesion, and a combination of abrasive wear and adhesion.

The failure modes of the SKD11 hardened ball surface that slide in relative movement to the grade SUS304 BA austenitic stainless steel with various contact pressures and 


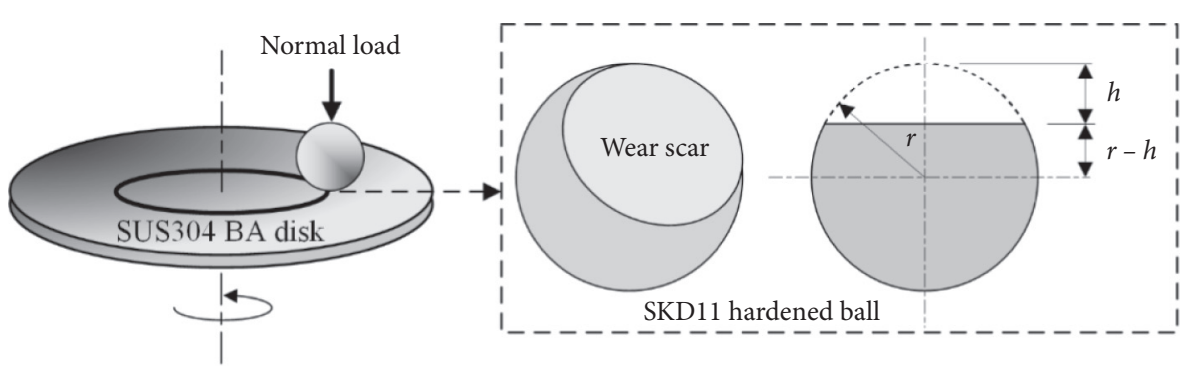

FIGURE 1: Illustration of the pin-on-disk test and a schematic diagram of a worn ball.

TABLE 2: Physical and mechanical properties of film coatings and SKD11 ball.

\begin{tabular}{lcccc}
\hline Film type & Color & Film thickness $(\mu \mathrm{m})$ & Surface roughness: Ra $(\mu \mathrm{m})$ & Hardness $(\mathrm{HV})$ \\
\hline DLC & Black & 1.20 & 0.079 & $2993 \pm 169$ \\
CrN & Silver & 2.95 & 0.101 & $1646 \pm 69$ \\
TiN & Gold & 1.79 & 0.091 & $2157 \pm 78$ \\
TiCN & Gray & 1.24 & 0.142 & $2765 \pm 144$ \\
& Noncoated (SKD11 hardened ball) & & 0.114 & $714^{*}$ \\
\hline
\end{tabular}

Remark: * Hardness values were obtained from the hardness tester.

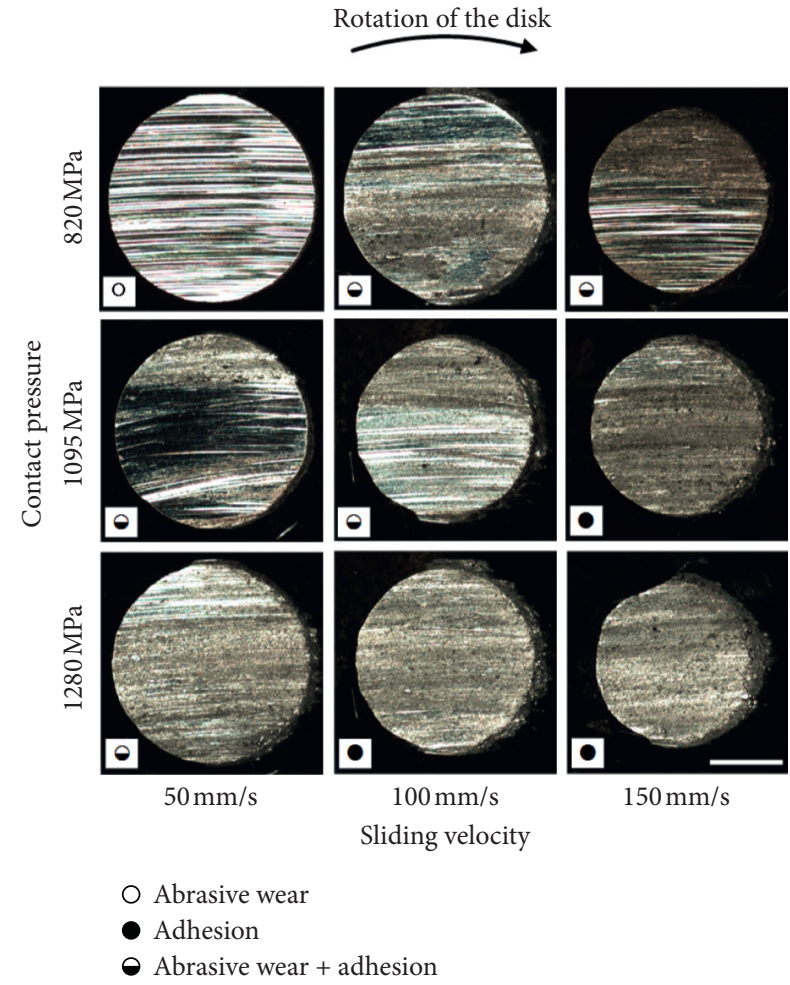

FIGURE 2: Characteristics of the contacting surface of an SKD11 hardened ball at the sliding distance of $1200 \mathrm{~m}$.

movement speeds, at $100 \mathrm{~m}$ intervals up to the test distance of $1200 \mathrm{~m}$, is shown in Table 3.

The results show that only the ball surface was tested under an $807 \mathrm{MPa}$ contact pressure with a $50 \mathrm{~mm} / \mathrm{s}$ sliding velocity. Abrasive wear occurs without material transferring and adhering to the ball surface throughout the testing distance of $1200 \mathrm{~m}$. When increasing the sliding velocity, the adhesion of the mating material to the contacting surface of the ball will appear. Additionally, the severity of the adhesion when increasing the pressure between the contact surfaces was increased. The adhesion of the workpiece material on the ball surface begins in combination with abrasive wear as the test distance increased while the intensity of the adhesion increased by finding workpiece material debris that adhered to the surface of the ball. It was noticed that the workpiece material that adhered to the ball surface can fall from the surface of the ball during the relative movement and can adhere to the material again, which is an indeterminate form.

When considering the coefficient of friction from the tests at a distance of $100 \mathrm{~m}$, as in Figure 3, including the failure modes of die material in Table 3, the friction coefficient between the contact surfaces of the adhesion cases has a high value, which is consistent with previous research $[9,11,17,19,20,30]$. The average friction coefficient between the contact surfaces of the SKD11 hardened ball and SUS304 BA disk was in the 0.5-0.7 range, with a pattern of abrasive wear on the ball surface. While the test conditions found adhesion on the ball surface including abrasive wear, the average friction between the contact surfaces was higher than the above case, which was greater than 0.7 . This is due to the materials adhered to the surface of the ball, which are hard due to the mechanism of strain hardening from plastic deformation plowing the mating material during the tests, causing the coefficient of friction between the contact surfaces to be higher. It seems that the severity of the workpiece material transferring and adhering onto the ball surface increases as the contact pressure and the sliding velocity increase.

3.2. Wear Characteristics of Hardened SKD11 Tool Steel. The quantitative evaluation of the wear of hardened SKD11 tool steel in sliding relative movement to the SUS304 BA stainless-steel sheet at various test conditions in terms of volume versus sliding distance is shown in Figures 4-6. 
TABLE 3: Failure modes of the SKD11 hardened ball contacting surface.

\begin{tabular}{|c|c|c|c|c|c|c|c|c|c|c|c|c|c|}
\hline \multirow{2}{*}{$\begin{array}{l}\text { Contact pressure } \\
(\mathrm{MPa})\end{array}$} & \multirow{2}{*}{$\begin{array}{l}\text { Sliding velocity } \\
\qquad(\mathrm{mm} / \mathrm{s})\end{array}$} & \multicolumn{12}{|c|}{ Sliding distance $\left(10^{2} \mathrm{~m}\right)$} \\
\hline & & 1 & 2 & 3 & 4 & 5 & 6 & 7 & 8 & 9 & 10 & 11 & 12 \\
\hline \multirow[t]{3}{*}{807} & 50 & $\bigcirc$ & 0 & 0 & $\bigcirc$ & O & O & 0 & $\bigcirc$ & ○ & 0 & 0 & O \\
\hline & 100 & $\bigcirc$ & $\bigcirc$ & $\bigcirc$ & $\bigcirc$ & $\ominus$ & O & $\bigcirc$ & $\ominus$ & O & $\bigcirc$ & $\bigcirc$ & $\ominus$ \\
\hline & 150 & 0 & 0 & 0 & $\theta$ & $\ominus$ & $\ominus$ & $\ominus$ & $\ominus$ & $\ominus$ & $\ominus$ & $\ominus$ & ○ \\
\hline \multirow[t]{3}{*}{1095} & 50 & 0 & 0 & 0 & ○ & $\ominus$ & $\ominus$ & $\ominus$ & $\ominus$ & $\ominus$ & $\ominus$ & 0 & $\ominus$ \\
\hline & 100 & 0 & $\ominus$ & $\ominus$ & $\ominus$ & $\ominus$ & $\ominus$ & $\ominus$ & $\ominus$ & $\ominus$ & $\ominus$ & $\ominus$ & $\ominus$ \\
\hline & 150 & $\theta$ & $\ominus$ & $\ominus$ & 0 & $\ominus$ & $\ominus$ & $\ominus$ & $\ominus$ & $\theta$ & 0 & 0 & 0 \\
\hline \multirow[t]{3}{*}{1280} & 50 & $\ominus$ & $\ominus$ & $\ominus$ & 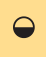 & $\ominus$ & $\ominus$ & $\ominus$ & $\ominus$ & $\ominus$ & $\ominus$ & $\bullet$ & $\ominus$ \\
\hline & 100 & 0 & $\theta$ & 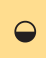 & ○ & $\theta$ & $\ominus$ & 0 & $\ominus$ & $\ominus$ & 0 & 0 & 0 \\
\hline & 150 & $\ominus$ & $\ominus$ & 0 & 0 & $\ominus$ & $\ominus$ & 0 & 0 & $\ominus$ & 0 & 0 & 0 \\
\hline
\end{tabular}

Abrasive wear,

Adhesion,

Abrasive wear + Adhesion

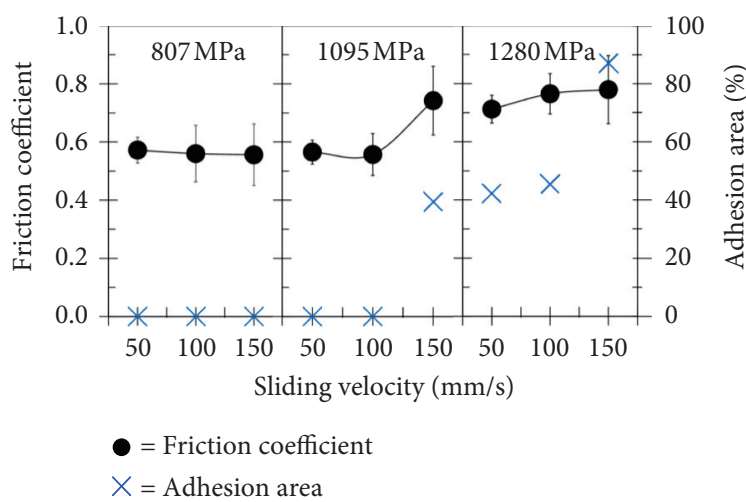

Figure 3: Coefficient of friction between the contacting surfaces and adhesion area.

Although stainless-steel adhesion was found on tool material during testing under various test conditions, the wear behavior of the hardened SKD11 cold work tool steel in the form of wear volume was dependent on sliding distance up to $1200 \mathrm{~m}$. It was still a positive linear relationship. The $R^{2}$ statistical values are greater than 0.90 , except for the test conditions at the $150 \mathrm{~mm} / \mathrm{s}$ sliding velocity and $1280 \mathrm{MPa}$ contact pressure, Figure 6, because, at $100 \mathrm{~m}$, the ball material had severe wear resulting in increased contact area. After this phenomenon, there was severe adhesion of the workpiece material on the surface of the tool material since the initial testing. The workpiece materials that adhered to

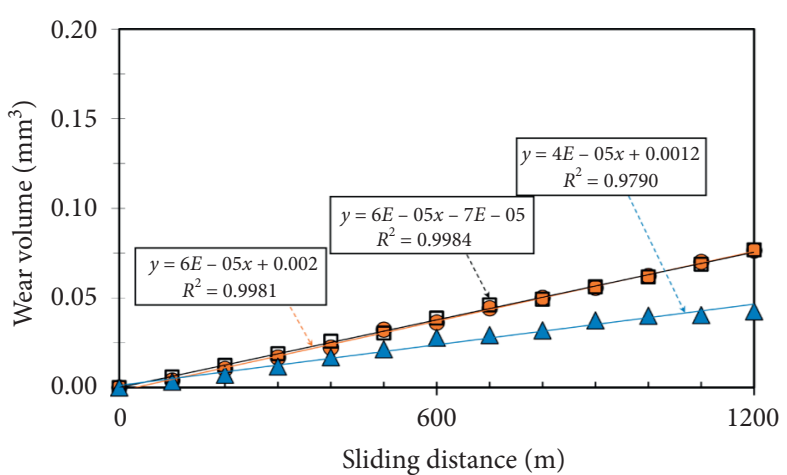

Contact pressure: $807 \mathrm{MPa}$

O Sliding velocity: $50 \mathrm{~mm} / \mathrm{s}$

口 Sliding velocity: $100 \mathrm{~mm} / \mathrm{s}$

$\Delta$ Sliding velocity: $150 \mathrm{~mm} / \mathrm{s}$

FIGURE 4: Wear volume data of hardened SKD11 balls under sliding conditions and $807 \mathrm{MPa}$ of contact pressure.

the ball surface reduced the amount of wear material, as can be seen from the slope of the wear volume curve, which has a stable trend after the test at $100 \mathrm{~m}$ until $1200 \mathrm{~m}$, and as a result, the $R^{2}$ statistical value of the linear equation model was low when compared to other test conditions. Therefore, when comparing the specific wear rate of the balls at a sliding distance of $1200 \mathrm{~m}$, as shown in Figure 7, the results show that when the normal load and the sliding velocity increased, the severity of adhesion on the tool material also increased 


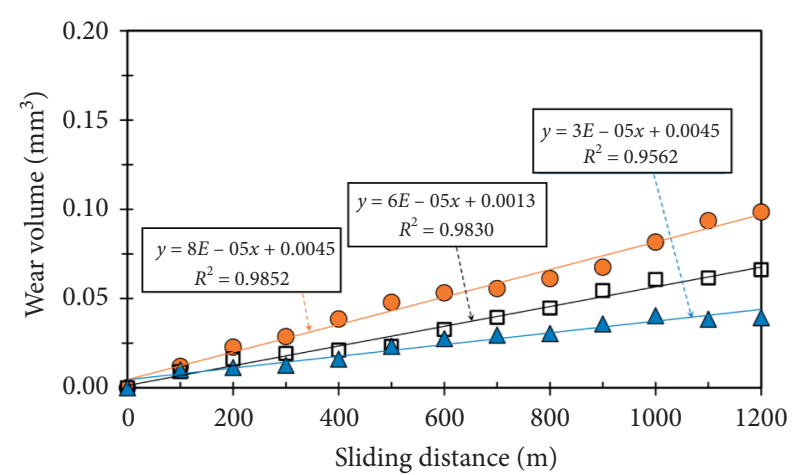

Contact pressure: $1095 \mathrm{MPa}$

o Sliding velocity: $50 \mathrm{~mm} / \mathrm{s}$

$\square$ Sliding velocity: $100 \mathrm{~mm} / \mathrm{s}$

$\Delta$ Sliding velocity: $150 \mathrm{~mm} / \mathrm{s}$

FIGURE 5: Wear volume data of hardened SKD11 balls under sliding conditions and $1095 \mathrm{MPa}$ of contact pressure.

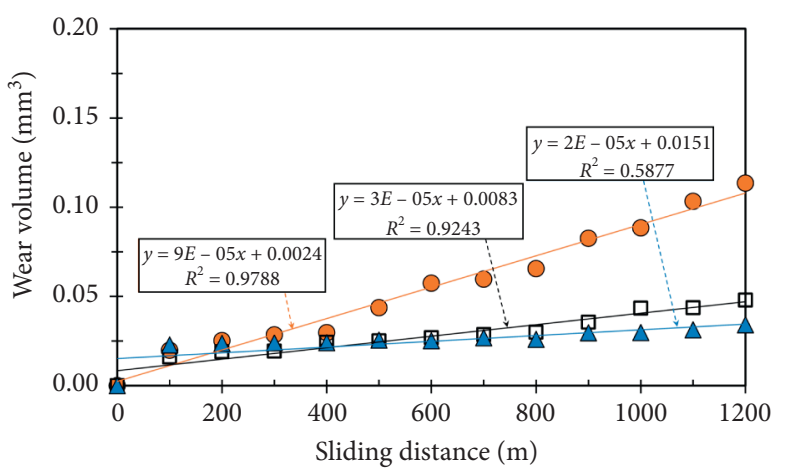

Contact pressure: $1280 \mathrm{MPa}$

○ Sliding velocity: $50 \mathrm{~mm} / \mathrm{s}$

$\square$ Sliding velocity: $100 \mathrm{~mm} / \mathrm{s}$

$\Delta$ Sliding velocity: $150 \mathrm{~mm} / \mathrm{s}$

FIGURE 6: Wear volume data of hardened SKD11 balls under sliding conditions and $1280 \mathrm{MPa}$ of contact pressure.

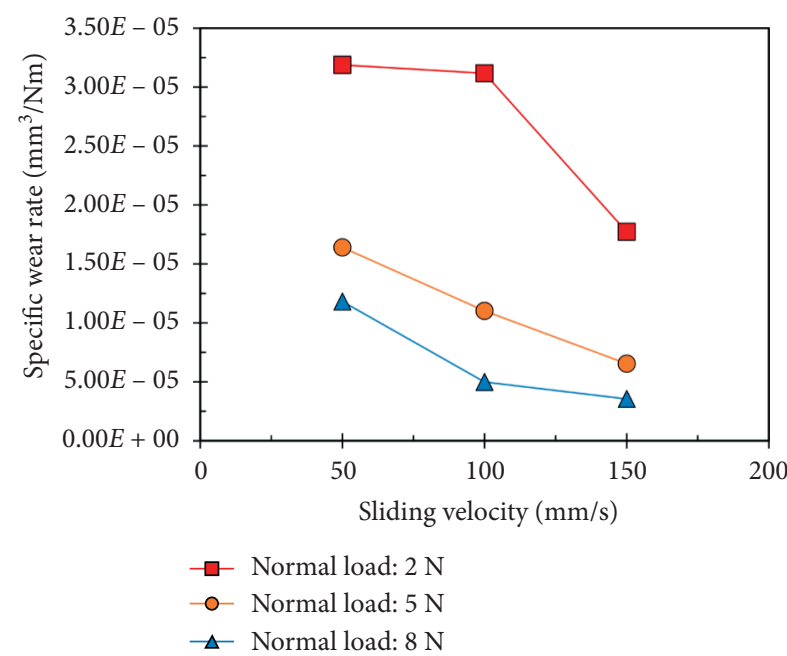

FIGURE 7: Specific wear rate varying with sliding velocity under normal loads. and the specific wear rate of hardened grade SKD11 cold work tool steel tended to decrease.

The failure characteristics of the ball at $1200 \mathrm{~m}$, as in Figure 2, confirm that the adhesion of the mating material on the ball surface can reduce the amount of material removal. Especially when there is severe adhesion on the ball surface throughout the sliding distance, the ball will lose less material. This results in a low specific wear rate when compared to hardened SKD11 balls with abrasive wear or abrasive wear combined with adhesion. However, this phenomenon yields poor quality contact surfaces and directly affects the adhesive wear of the workpiece material.

3.3. Antiadhesion Performance of Film Coatings. The results of tribological simulating tests, Table 4, demonstrate the different performances of each film type to prevent adhesion on the hardened SKD11 ball surface. The failure modes of the ball surface still occur in 3 forms, just like the noncoated ball. The TiCN-coated ball had the highest adhesion intensity. Next was the CrN-coated ball and the TiN-coated ball. Only the DLC-coated ball did not have workpiece material adhesion on the surface in the test with an $807 \mathrm{MPa}$ contact pressure and 50 and $100 \mathrm{~mm} / \mathrm{s}$ sliding velocities over the $1200 \mathrm{~m}$ sliding distance. However, when the sliding velocity and contact pressure increased, the workpiece material adhered to the DLC-coated ball surface as well.

The adhesion phenomenon of SUS304 BA material to the surface of the hardened grade SKD11 tool material and the tool material coated with various types of solid film has indefinite characteristics that make it difficult to quantitatively predict the material transfer. These results confirm the previous works that show each type of solid film has different antiadhesion performances. DLC film has better performance for reducing the problem of SUS304 material transferring and adhering onto hardened SKD11 forming tools when compared to the other types of solid films.

3.4. Friction and Wear Characteristics of Coated Balls against SUS304 BA Material. Figure 8 shows that the DLC-coated balls provide an extremely low coefficient of friction between the contacting surface when sliding on the SUS304 BA material (0.047-0.118). The hardened SKD11 balls coated with nitrogen-based solid films have a higher coefficient of friction in the range of 0.615 to 0.870 . This is likely due to the workpiece material adhesion on the ball surface, which is equivalent to the noncoated ball in the case of adhesion. Significant low friction values of DLC films are due to the extreme hardness of this film and its low surface roughness, which has been described in Ref. [33], including not having the influence of adhesion on the film surface. When considering the influence of contact pressure and sliding velocity, it seems that these variables do not significantly affect the friction coefficient between the contacting surfaces.

In addition to how the hardness of the DLC film affects the friction coefficient between the contact surfaces, it also clearly affects the wear volume of the tool material, as can be seen in the wear behavior of the coated balls in Figure 9. The high film hardness will prevent damage to the film coating 
TABLE 4: Failure modes of the contacting surface of coated balls.

\begin{tabular}{|c|c|c|c|c|c|c|c|c|c|c|c|c|c|c|}
\hline \multirow{2}{*}{$\begin{array}{l}\text { Film } \\
\text { type }\end{array}$} & \multirow{2}{*}{$\begin{array}{c}\text { Contact pressure } \\
(\mathrm{MPa})\end{array}$} & \multirow{2}{*}{$\begin{array}{c}\text { Sliding } \\
\text { velocity } \\
(\mathrm{mm} / \mathrm{s})\end{array}$} & \multicolumn{12}{|c|}{ Sliding distance $\left(10^{2} \mathrm{~m}\right)$} \\
\hline & & & 1 & 2 & 3 & 4 & 5 & 6 & 7 & 8 & 9 & 10 & 11 & 12 \\
\hline \multirow[t]{9}{*}{ DLC } & 807 & 50 & $\mathrm{O}$ & 0 & 0 & $\mathrm{O}$ & 0 & O & O & $\mathrm{O}$ & O & $\mathrm{O}$ & 0 & 0 \\
\hline & & 100 & 0 & 0 & 0 & 0 & 0 & 0 & 0 & 0 & 0 & 0 & 0 & 0 \\
\hline & & 150 & $\mathrm{O}$ & $\mathrm{O}$ & O & 0 & O & O & $\theta$ & $\ominus$ & ○ & $\ominus$ & $\ominus$ & $\theta$ \\
\hline & 1095 & 50 & 0 & 0 & $\theta$ & $\theta$ & $\theta$ & $\ominus$ & $\ominus$ & $\ominus$ & $\theta$ & $\theta$ & $\theta$ & $\theta$ \\
\hline & & 100 & O & $\mathrm{O}$ & O & $\ominus$ & $\ominus$ & $\ominus$ & $\theta$ & $\ominus$ & $\theta$ & $\theta$ & $\theta$ & $\theta$ \\
\hline & & 150 & $\mathrm{O}$ & $\Theta$ & ○ & $\ominus$ & $\ominus$ & $\ominus$ & $\ominus$ & $\ominus$ & ○ & $\ominus$ & $\theta$ & $\theta$ \\
\hline & 1280 & 50 & $\mathrm{O}$ & 0 & 0 & 0 & 0 & 0 & $\ominus$ & $\theta$ & $\theta$ & $\theta$ & $\theta$ & $\theta$ \\
\hline & & 100 & 0 & 0 & $\theta$ & $\theta$ & $\theta$ & $\theta$ & $\theta$ & $\theta$ & $\theta$ & $\theta$ & $\theta$ & $\theta$ \\
\hline & & 150 & 0 & 0 & 0 & 0 & $\ominus$ & $\ominus$ & $\ominus$ & $\theta$ & $\theta$ & $\ominus$ & $\ominus$ & $\theta$ \\
\hline \multirow[t]{9}{*}{$\mathrm{CrN}$} & 807 & 50 & $\theta$ & 0 & 0 & $\theta$ & 0 & $\theta$ & 0 & 0 & 0 & 0 & $\theta$ & $\theta$ \\
\hline & & 100 & $\theta$ & 0 & $\theta$ & $\theta$ & $\ominus$ & 0 & $\theta$ & $\theta$ & 0 & $\theta$ & $\theta$ & $\theta$ \\
\hline & & 150 & 0 & 0 & 0 & $\ominus$ & $\ominus$ & $\theta$ & $\theta$ & $\theta$ & $\theta$ & $\theta$ & $\theta$ & $\theta$ \\
\hline & 1095 & 50 & $\theta$ & 0 & $\theta$ & $\theta$ & $\theta$ & 0 & $\theta$ & 0 & 0 & $\theta$ & 0 & 0 \\
\hline & & 100 & $\theta$ & $\theta$ & $\theta$ & $\theta$ & $\theta$ & 0 & 0 & 0 & 0 & 0 & 0 & 0 \\
\hline & & 150 & $\theta$ & 0 & $\theta$ & $\theta$ & $\theta$ & 0 & 0 & 0 & 0 & 0 & 0 & 0 \\
\hline & 1280 & 50 & $\theta$ & 0 & $\theta$ & $\theta$ & $\theta$ & $\theta$ & $\theta$ & $\theta$ & $\theta$ & 0 & 0 & 0 \\
\hline & & 100 & $\theta$ & $\theta$ & $\theta$ & $\ominus$ & $\theta$ & $\theta$ & 0 & 0 & 0 & 0 & 0 & 0 \\
\hline & & 150 & $\theta$ & 0 & 0 & 0 & 0 & 0 & 0 & 0 & 0 & 0 & 0 & 0 \\
\hline \multirow[t]{9}{*}{ TiN } & 807 & 50 & $\theta$ & 0 & $\theta$ & $\theta$ & $\theta$ & $\theta$ & $\theta$ & $\theta$ & $\theta$ & $\theta$ & $\theta$ & $\theta$ \\
\hline & & 100 & $\theta$ & $\theta$ & $\theta$ & $\theta$ & $\ominus$ & $\theta$ & $\theta$ & 0 & 0 & $\theta$ & $\theta$ & $\theta$ \\
\hline & & 150 & $\theta$ & 0 & $\theta$ & $\theta$ & $\theta$ & $\theta$ & $\ominus$ & $\theta$ & 0 & $\theta$ & 0 & $\theta$ \\
\hline & 1095 & 50 & $\theta$ & $\theta$ & $\ominus$ & $\theta$ & $\theta$ & $\theta$ & $\theta$ & $\theta$ & $\theta$ & $\theta$ & $\theta$ & $\theta$ \\
\hline & & 100 & 0 & 0 & 0 & $\theta$ & $\theta$ & 0 & 0 & 0 & 0 & 0 & 0 & $\theta$ \\
\hline & & 150 & $\theta$ & $\theta$ & $\ominus$ & $\ominus$ & $\theta$ & $\ominus$ & $\ominus$ & $\theta$ & $\theta$ & $\theta$ & $\theta$ & 0 \\
\hline & 1280 & 50 & 0 & 0 & $\theta$ & $\theta$ & $\theta$ & $\theta$ & $\theta$ & $\theta$ & 0 & 0 & 0 & 0 \\
\hline & & 100 & $\theta$ & $\theta$ & $\theta$ & $\theta$ & $\ominus$ & $\ominus$ & $\ominus$ & 0 & 0 & $\theta$ & 0 & 0 \\
\hline & & 150 & 0 & 0 & $\theta$ & 0 & $\theta$ & 0 & 0 & 0 & 0 & 0 & 0 & 0 \\
\hline \multirow[t]{9}{*}{ TiCN } & 807 & 50 & $\theta$ & $\theta$ & $\theta$ & $\theta$ & $\theta$ & $\theta$ & $\theta$ & $\theta$ & $\theta$ & $\theta$ & $\theta$ & $\theta$ \\
\hline & & 100 & $\theta$ & 0 & $\ominus$ & $\ominus$ & $\ominus$ & $\ominus$ & $\theta$ & $\theta$ & 0 & $\theta$ & $\theta$ & $\theta$ \\
\hline & & 150 & $\theta$ & 0 & 0 & $\theta$ & $\theta$ & 0 & 0 & 0 & 0 & 0 & 0 & 0 \\
\hline & 1095 & 50 & 0 & 0 & $\ominus$ & $\theta$ & $\ominus$ & 0 & 0 & 0 & 0 & $\ominus$ & $\theta$ & $\theta$ \\
\hline & & 100 & 0 & 0 & $\theta$ & $\theta$ & $\theta$ & 0 & 0 & 0 & 0 & 0 & 0 & 0 \\
\hline & & 150 & e & 0 & 0 & 0 & 0 & 0 & 0 & 0 & 0 & 0 & 0 & 0 \\
\hline & 1280 & 50 & 0 & 0 & $\theta$ & $\theta$ & 0 & 0 & 0 & 0 & 0 & 0 & 0 & 0 \\
\hline & & 100 & 0 & 0 & 0 & 0 & O & 0 & 0 & 0 & 0 & 0 & 0 & 0 \\
\hline & & 150 & 0 & 0 & 0 & 0 & $\theta$ & 0 & 0 & 0 & 0 & 0 & 0 & O \\
\hline
\end{tabular}

O Abrasive wear,

- Adhesion,

- Abrasive wear + Adhesion 


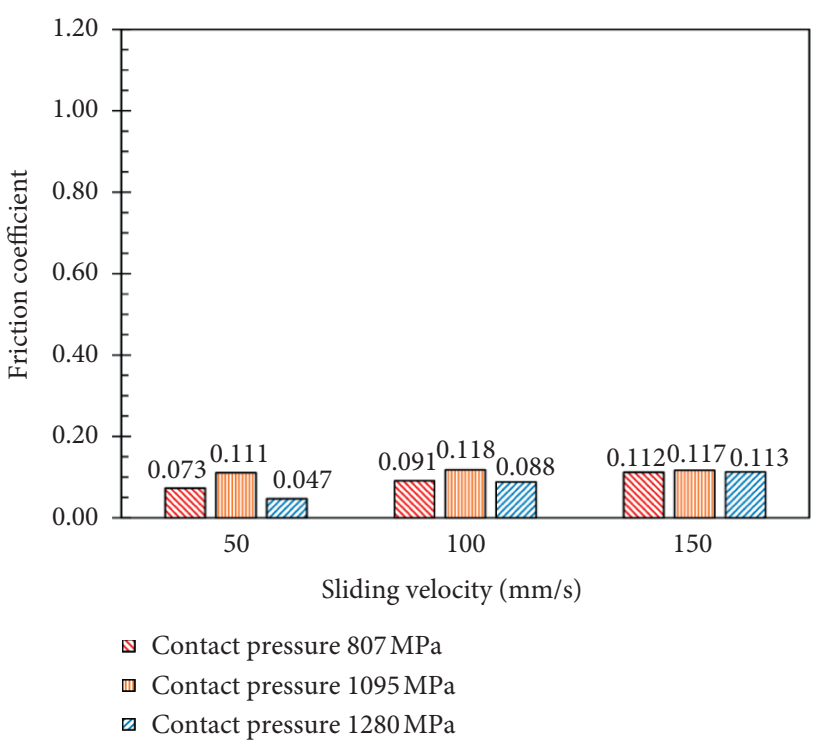

(a)

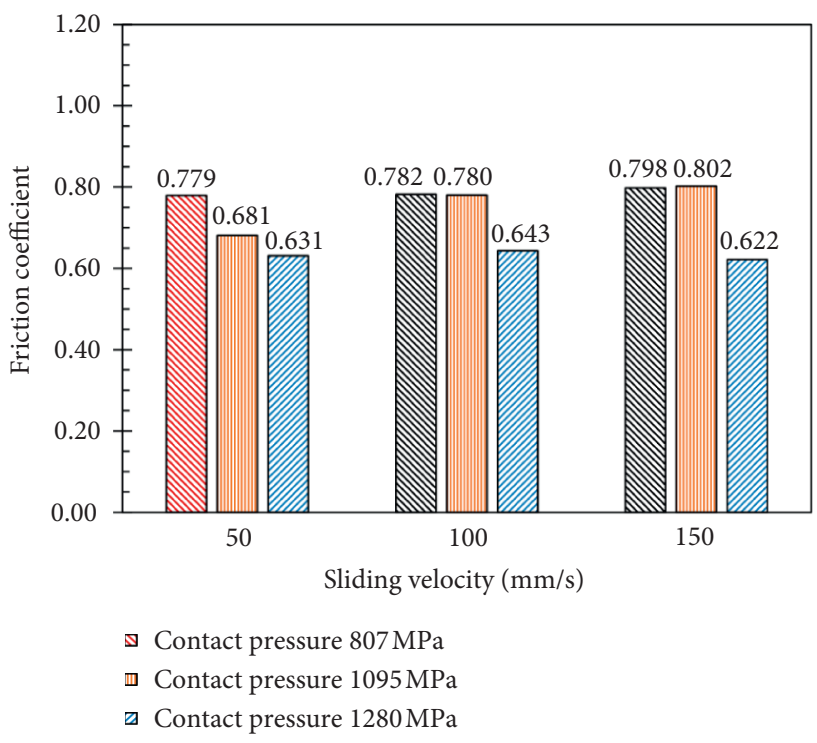

(c)

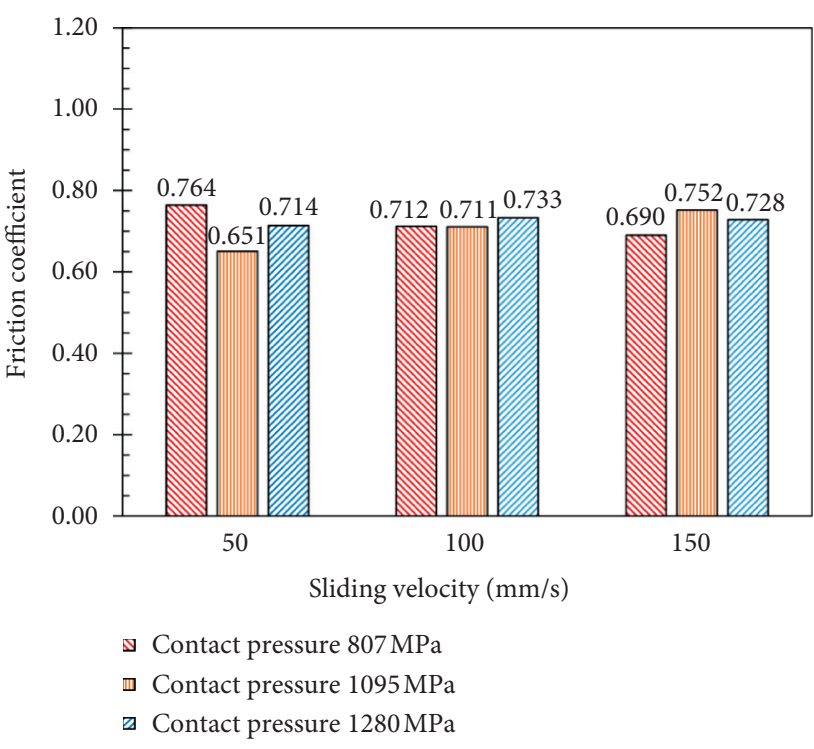

(b)

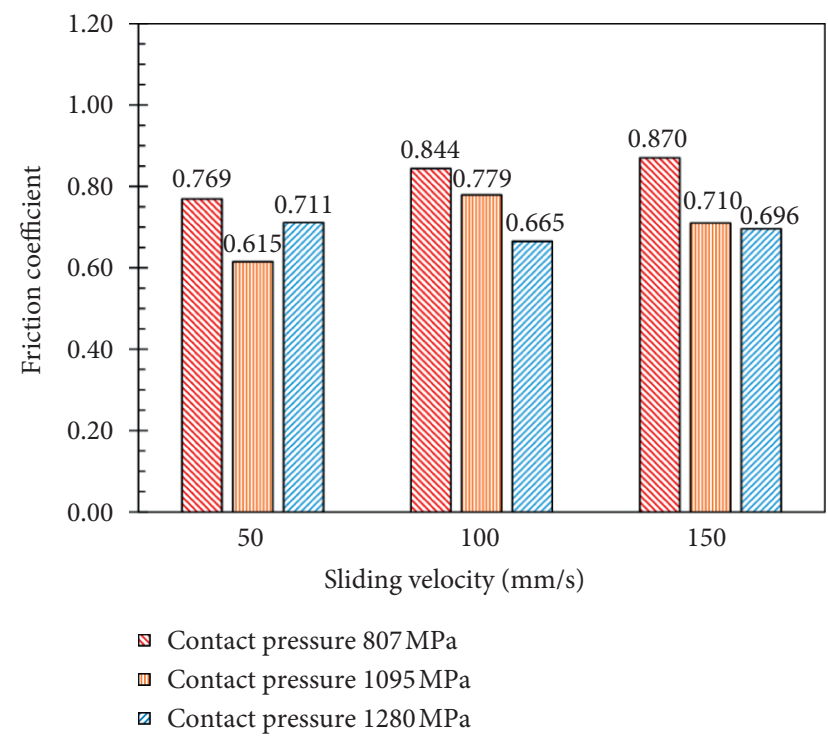

(d)

FIgURE 8: Friction coefficient of coated balls against SUS304 BA material. (a) DLC-coated ball. (b) CrN-coated ball. (c) TiN-coated ball. (d) TiCN-coated ball.

and substrate, resulting in a low contact area with the mating material, especially when being used in conditions of high contact pressure, such as certain metal forming processes. The influence of film hardness on wear volume can be confirmed by the wear behavior of the TiCN-coated ball, which has the second-highest film hardness value after DLC. For the balls that are coated with $\mathrm{CrN}$ and TiN films, which have lower hardness values than both DLC and TiCN films, which are in the range of 1600-2200 HV, the wear behavior will continuously increase when the sliding distance increases. Only in the test under a low contact pressure of $807 \mathrm{MPa}$ did the balls coated with $\mathrm{CrN}$ and TiN films show wear volume less than the balls coated with TiCN film.
The simulation testing of tribology between the contacting surface of hardened grade SKD11 cold work tool steel relatively sliding on grade SUS304 BA austenitic stainlesssteel sheet under dry conditions shows that the main problem is workpiece material adhesion on the tool surface. The severity of the workpiece material adhesion is proportional to the sliding velocity and the contact pressure between the contacting surfaces. However, the wear volume of the tool material is reversed because once the workpiece material has adhered to the tool surface, it reduces the tool material removal during movement, which directly affects the study of tool wear behavior. However, the wear behavior of the tool material relative to the sliding distance is still a 

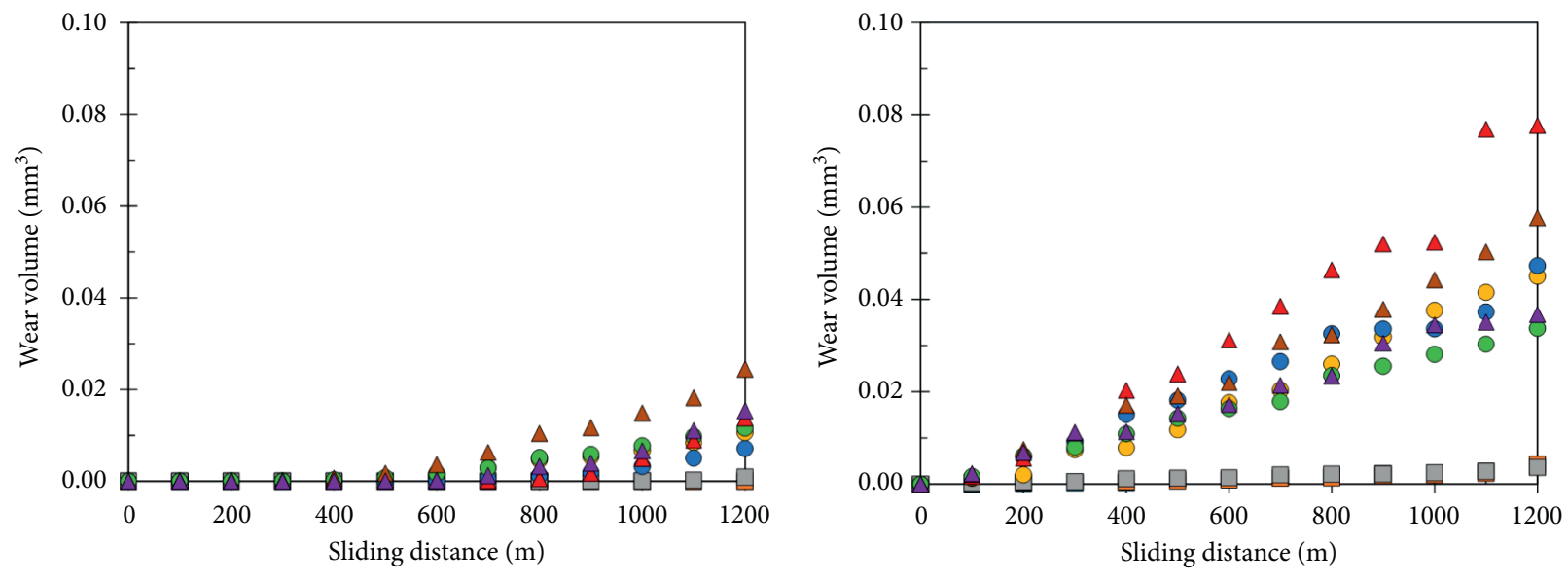

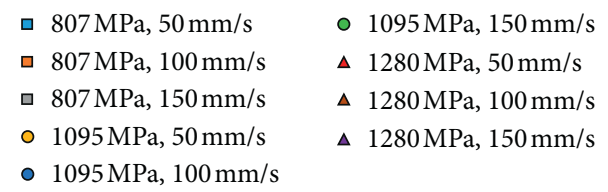

(a)

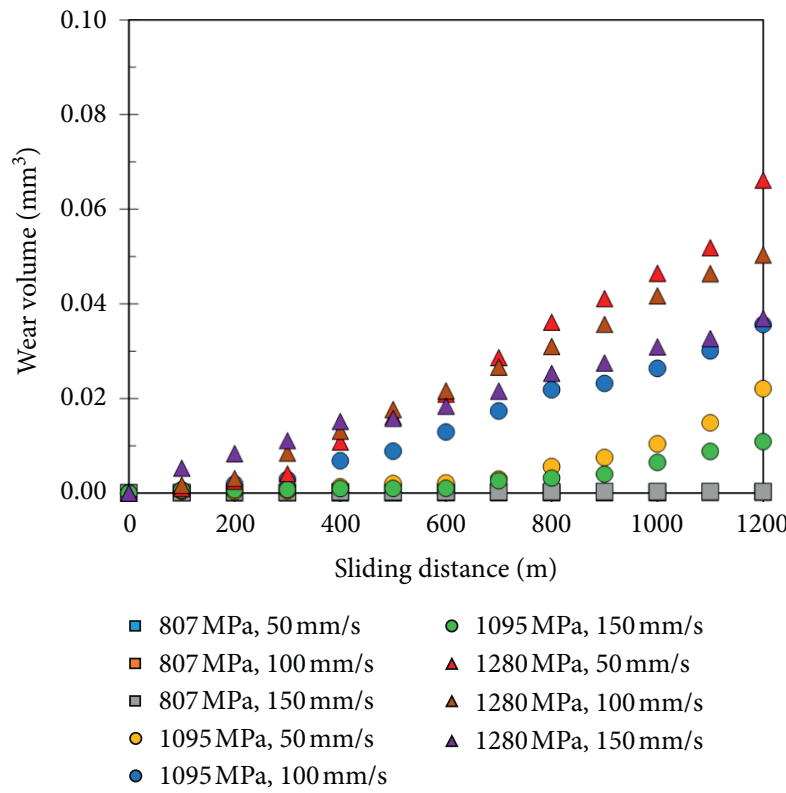

(c)
$807 \mathrm{MPa}, 50 \mathrm{~mm} / \mathrm{s}$
- $807 \mathrm{MPa}, 100 \mathrm{~mm} / \mathrm{s}$
- $1095 \mathrm{MPa}, 150 \mathrm{~mm} / \mathrm{s}$
$807 \mathrm{MPa}, 150 \mathrm{~mm} / \mathrm{s}$
- $1095 \mathrm{MPa}, 50 \mathrm{~mm} / \mathrm{s}$
- $1095 \mathrm{MPa}, 100 \mathrm{~mm} / \mathrm{s}$
$\Delta 1280 \mathrm{MPa}, 50 \mathrm{~mm} / \mathrm{s}$
$\Delta 1280 \mathrm{MPa}, 100 \mathrm{~mm} / \mathrm{s}$
$\Delta 1280 \mathrm{MPa}, 150 \mathrm{~mm} / \mathrm{s}$

(b)

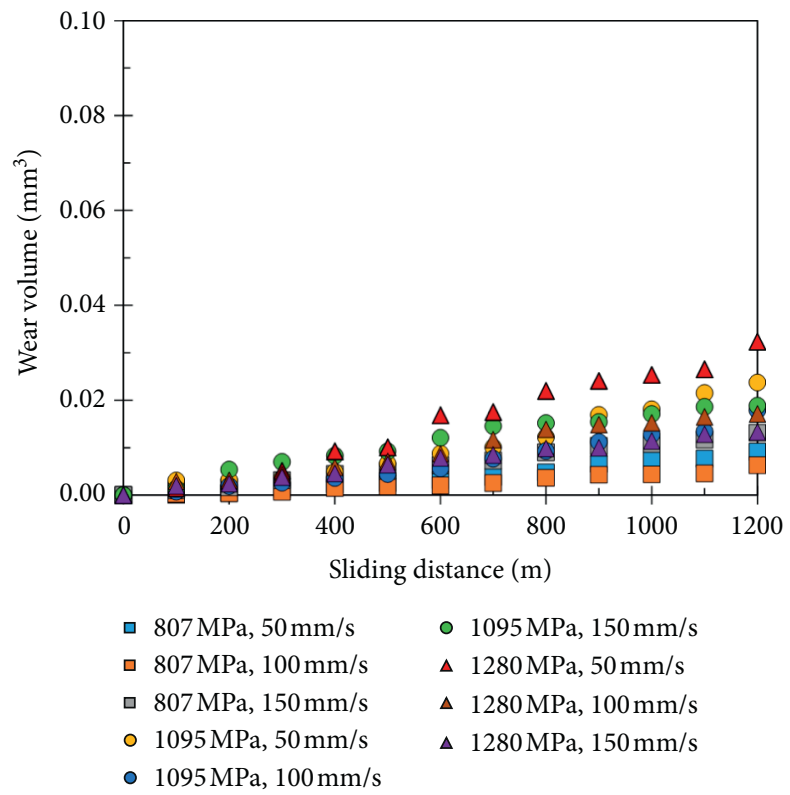

(d)

Figure 9: Wear volume of coated balls. (a) DLC-coated ball. (b) CrN-coated ball. (c) TiN-coated ball. (d) TiCN-coated ball.

positive linear relationship, which is consistent with Ref. [33]. This wear behavior is the type that occurs under dry conditions or having inefficient lubrication systems. The $R^{2}$ value of the linear equation model of most of the wear volume is higher than 0.9 , and when there is a severe adhesion of workpiece material on the tool surface, the $R^{2}$ value will decrease.

It is well known that increasing the tribological efficiency of tool material with a solid film coating is the cost of production. Due to the hardness of the film, it can prevent plastic deformation of the tool material, resulting in low wear, especially when used under high contact pressure conditions. However, this study found that the hardness of the film does not prevent workpiece material adhesion on the tool surface. In sheet metal cold forming, workpiece material adhesion to the tool surface is one of the indicators in determining tool life. Therefore, tool designers must choose a suitable solid film for use by the type of mating material.

\section{Conclusions}

From the study of tribological behavior between tool materials and grade SUS304 BA stainless-steel workpiece material using the pin-on-disk method, the results are concluded as follows: 
(1) The sliding velocity and the contact pressure influence the adhesion behavior of the workpiece material. When both variables increased, the intensity of the adhesion increased.

(2) The friction coefficient between the contacting surface is related to the adhesion behavior on the tool material surface. If adhesion does not appear, the friction coefficient between the ball and workpiece surfaces under dry conditions is in the $0.5-0.7$ range, and when adhesion to the contact surface has occurred, the friction coefficient will increase to $0.7-0.9$.

(3) The severity of adhesion on the tool material surface affects the quantification of the tool wear since the workpiece material that adhered will prevent tool material removal. Therefore, the wear behavior obtained from this study will influence quantifying workpiece material adhesion.

(4) The hardness of the film that is coated on the tool material surface is useful for preventing tool material wear, especially when working under high contact pressure. However, the film coating hardness does not increase the efficiency of preventing workpiece adhesion.

(5) DLC film has the most effective protection for the adhesion of grade SUS304 BA stainless steel on the surface of the tool material when compared with the other types of solid films that were studied. In addition, using hardened SKD11 noncoated ball under low sliding velocity and low contact pressure also has more effectiveness in preventing adhesion of SUS304 BA stainless steel on the ball surface than $\mathrm{CrN}$, TiN, and TiCN-coated balls.

\section{Data Availability}

Previously reported data were used to support this study. These prior studies are cited at relevant places within the text as references.

\section{Conflicts of Interest}

The authors declare no conflicts of interest.

\section{Acknowledgments}

The authors gratefully acknowledge Faculty of Engineering Srinakarinwirot University who provide research grant from the annual income budget 2019 .

\section{References}

[1] K. Lange, Handbook of Metal Forming, McGraw-Hill, New York, NY, USA, 1985.

[2] F. Vollertsen and F. Schmidt, "Dry metal forming: definition, chances and challenges," International Journal of Precision Engineering and Manufacturing-Green Technology, vol. 1, no. 1, pp. 59-62, 2014.

[3] M. Murakawa, N. Koga, and T. Kumagai, "Deep-drawing of aluminum sheets without lubricant by use of diamond-like carbon coated dies," Surface and Coatings Technology, vol. 7677, pp. 553-558, 1995.

[4] T. Horiuchi, S. Yoshihara, and Y. Iriyama, "Dry deep drawability of A5052 aluminum alloy sheet with DLC-coating," Wear, vol. 286-287, pp. 79-83, 2012.

[5] T. Sato and T. Besshi, "Anti-galling evaluation in aluminum sheet forming," Journal of Materials Processing Technology, vol. 83, no. 1-3, pp. 185-191, 1998.

[6] T. Sato, T. Besshi, I. Tsutsui, and T. Morimoto, "Anti-galling property of a diamond-like carbon coated tool in aluminum sheet forming," Journal of Materials Processing Technology, vol. 104, no. 1-2, pp. 21-24, 2000.

[7] S. Kataoka, M. Murakawa, T. Aizawa, and H. Ike, "Tribology of dry deep-drawing of various metal sheets with use of ceramics tools," Surface and Coatings Technology, vol. 177-178, pp. 582-590, 2004.

[8] B. Podgornik, S. Hogmark, and O. Sandberg, "Influence of surface roughness and coating type on the galling properties of coated forming tool steel," Surface and Coatings Technology, vol. 184, no. 2-3, pp. 338-348, 2004.

[9] B. Podgornik, S. Hogmark, and O. Sandberg, "Proper coating selection for improved galling performance of forming tool steel," Wear, vol. 261, no. 1, pp. 15-21, 2006.

[10] Y. Abe, W. Daodon, N. Takahashi, and K. Mori, "Improvement of seizure resistance by roughening surface of stainless steel drawn cup in ironing using die having lubricant pockets," Production Engineering Research and Development, vol. 10, no. 6, pp. 551-562, 2016.

[11] A. Gåård, P. V. Krakhmalev, J. Bergström, and N. Hallbäck, "Galling resistance and wear mechanisms-cold work tool materials sliding against carbon steel sheets," Tribology Letters, vol. 26, no. 1, pp. 67-72, 2007.

[12] P. Karlsson, A. Gåård, and P. Krakhmalev, "Influence of tool steel microstructure on friction and initial material transfer," Wear, vol. 319, no. 1-2, pp. 12-18, 2014.

[13] H. Kim, S. Han, Q. Yan, and T. Altan, "Evaluation of tool materials, coatings and lubricants in forming galvanized advanced high strength steels (AHSS)," CIRP Annals, vol. 57, no. 1, pp. 299-304, 2008.

[14] B. Sresomroeng, K. Lawanwong, V. Premanond et al., "Tribological behaviour of thin film coatings against high strength steels," International Journal of Abrasive Technology, vol. 2, no. 3, pp. 313-328, 2009.

[15] B. Sresomroeng, V. Premanond, P. Kaewtatip, A. Khantachawana, N. Koga, and S. Watanabe, "Anti-adhesion performance of various nitride and DLC films against high strength steel in metal forming operation," Diamond and Related Materials, vol. 19, no. 7-9, pp. 833-836, 2010.

[16] B. Sresomroeng, V. Premanond, P. Kaewtatip, A. Khantachawana, A. Kurosawa, and N. Koga, "Performance of CrN radical nitrided tools on deep drawing of advanced high strength steel," Surface and Coatings Technology, vol. 205, no. 17-18, pp. 4198-4204, 2011.

[17] H.-S. Choi, S.-G. Kim, P.-K. Seo, B.-M. Kim, B.-C. Cha, and D.-C. Ko, "Experimental investigation on galling performance of tool steel in stamping of UHSS sheets," International Journal of Precision Engineering and Manufacturing, vol. 15, no. 6, pp. 1101-1107, 2014.

[18] Y. Abe, T. Ohmi, K. Mori, and T. Masuda, "Improvement of formability in deep drawing of ultra-high strength steel sheets by coating of die," Journal of Materials Processing Technology, vol. 214, no. 9, pp. 1838-1843, 2014.

[19] W. Wang, X. Zheng, M. Hua, and X. Wei, "Influence of surface modification on galling resistance of DC53 tool steel 
against galvanized advanced high strength steel sheet," Wear, vol. 360-361, pp. 1-13, 2016.

[20] G. Li, X. Long, P. Yang, and Z. Liang, "Advance on friction of stamping forming," The International Journal of Advanced Manufacturing Technology, vol. 96, no. 1-4, pp. 21-38, 2018.

[21] 2013 Standard Test Methods for Tension Testing of Metallic Materials, ASTM E8/E8M-13a.

[22] 2000 Standard Test Method for Wear Testing with a Pin-onDisk Apparatus, ASTM G 99-95a.

[23] T. Altan and A. E. Tekkaya, Sheet Metal Forming Processes and Applications, ASM International, Cleveland, $\mathrm{OH}, \mathrm{USA}$, 2012.

[24] M. P. Pereira, W. Yan, and B. F. Rolfe, "Contact pressure evolution and its relation to wear in sheet metal forming," Wear, vol. 265, no. 11-12, pp. 1687-1699, 2008.

[25] B. Bhushan, Modern Tribology Handbook, CRC Press LLC, Boca Raton, FL, USA, 2001.

[26] H. Kim, T. Altan, and Q. Yan, "Evaluation of stamping lubricants in forming advanced high strength steels (AHSS) using deep drawing and ironing tests," Journal of Materials Processing Technology, vol. 209, no. 8, pp. 4122-4133, 2009.

[27] T. Altan, S. Oh, and H. Gegel, Metal Forming: Fundamentals and Applications, American Society for Metals, Cleveland, OH, USA, 1983.

[28] V. Boljanovic, Sheet Metal Stamping Dies: Die Design and DieMaking Practice, Industrial Press Inc, New York, NY, USA, 2013.

[29] Standard Components for Press Dies 2007.9-2008.8 Catalog, Misumi Corporation, Schaumburg, IL, USA, 2008.

[30] A. Gåård and R. M. Sarih, "Influence of tool material and surface roughness on galling resistance in sliding against austenitic stainless steel," Tribology Letters, vol. 46, no. 2, pp. 179-185, 2012.

[31] J. Steiner and M. Merklein, "Investigation of influencing parameters for tribological conditions in dry forming processes," Acta Metallurgica Sinica (English Letters), vol. 28, no. 12, pp. 1435-1441, 2015.

[32] G. W. Stachowiak and A. W. Batchelor, Engineering Tribology, Elsevier Butterworth-Heinemann, Oxford, UK, 2005.

[33] G. W. Stachowiak, Wear-Materials, Mechanisms and Practice, John Wiley \& Sons Ltd, Hoboken, NJ, USA, 2005. 